\title{
Splenic hypereosinophilia in anaphylaxis-related death: different assessments depending on different types of allergens?
}

\author{
Luca Reggiani Bonetti • Livia Maccio • Nicoletta Trani • \\ Erjon Radheshi • Cristian Palmiere
}

Received: 4 January 2014 / Accepted: 16 April 2014 /Published online: 1 May 2014

(C) Springer-Verlag Berlin Heidelberg 2014

\begin{abstract}
The aim of this study was to evaluate splenic eosinophil and mast cell accumulation using pagoda red stain in a series of anaphylaxis-related deaths that underwent medicolegal investigations. Our goal was to assess whether fatal reactions to insect stings, intramuscularly administered antibiotics and intravenously injected contrast media are responsible for specific patterns of eosinophil and mast cell accumulation. Two study groups were prospectively formed, an anaphylaxis-related death group and a control group. Autopsy, histology (haematoxylin-eosin stain, pagoda red stain and immunohistochemistry using anti-tryptase antibodies), toxicology and postmortem biochemistry (beta-tryptase, total IgE and specific IgE) were performed in all cases. All tested parameters (spleen weight, beta-tryptase and total IgE levels as well as eosinophil, mast cell and degranulated mast cell numbers in the spleen) were significantly higher in the anaphylaxis-related death group. No statistically significant differences were observed among the various groups (intramuscular antibiotic injection, intravenous contrast medium administration and stinging insects) in any combination, suggesting that mast cell and eosinophil accumulation in the spleen during anaphylaxis does
\end{abstract}

\footnotetext{
L. Reggiani Bonetti · L. Maccio

Department of Diagnostic Medicine and Public Health, University of Modena and Reggio Emilia - Section

of Anatomia Patologica, Modena, Italy

N. Trani $\cdot$ E. Radheshi

Department of Diagnostic Medicine and Public Health,

University of Modena and Reggio Emilia - Section

of Medicina Legale, Modena, Italy

C. Palmiere $(\bowtie)$

University Center of Legal Medicine, Lausanne University Hospital,

21 Rue du Bugnon, 1011 Lausanne, Switzerland

e-mail: cristian.palmiere@chuv.ch
}

not have any specific pattern related to the triggering allergen. Despite a lower sensitivity than immunohistochemical staining in discriminating eosinophil and mast cells, pagoda red stain allowed these cells to be identified and could therefore be proposed as a low-cost, first-line diagnostic procedure in those situations where immunohistochemistry is not systematically performed or cannot be carried out.

Keywords Anaphylaxis · Spleen · Eosinophils · Mast cells · Histology

\section{Introduction}

The term anaphylaxis indicates a severe, life-threatening, systemic hypersensitivity reaction that can be mediated by immunologic (IgE-mediated or allergic anaphylaxis) or nonimmunologic (nonallergic anaphylaxis) mechanisms. Clinical presentations and degrees of severity result from the sudden, systemic release of mediators from mast cells and basophils [1-5].

Anaphylaxis can present a series of unique challenges to the forensic pathologist as there may be a lack of macroscopic and microscopic findings. A clinical history of previous reactions to stinging insects, foods or drugs may be highly suggestive, though most forensic cases have incomplete medical records when bodies are admitted to the mortuary for medicolegal investigations. The diagnosis of fatal anaphylaxis must therefore often rely exclusively on circumstantial evidence when available and the exclusion of other potential causes of death after all postmortem investigations [5-9].

The accumulation of activated mast cells and eosinophils during anaphylaxis-related deaths in numerous organs, including the lungs and spleen, has been described by several 
authors [10-16]. Most researchers demonstrated the presence of eosinophils, mast cells and activated mast cells in organs and tissues using specific immunohistochemical staining with monoclonal antibodies. Even though immunohistochemistry remains the most sensitive diagnostic technique for mast cells and eosinophil detection in lung and spleen tissue samples, it is a relatively expensive tool that is not systematically used in all medico-legal centers [13].

Trani et al. reported that mast cells and eosinophils can be identified in spleen tissue samples in cases of fatal anaphylaxis using a nonspecific chemical stain, a cotton dye named pagoda red. In this study, the presence of mast cells and degranulated mast cells in four cases of fatal anaphylaxis following intramuscular penicillin and cephalosporin injection was postulated based on pagoda red staining results and subsequently confirmed by traditional immunohistochemistry [14].

Mast cells and basophils are the primary effector cells of immediate hypersensitivity reactions in humans [5]. On the other hand, clinical and experimental experience has always indicated that eosinophils are prominently engaged in allergic conditions and are implicated in the pathogenesis of anaphylaxis, albeit with functions that have always been topic of discussion [17].

Allergies are remarkably polymorphic in their clinical expression. This heterogeneity is usually explained by the location where the acute reaction occurs. Moreover, clinical features of anaphylaxis depend not only on the nature of the effector cells activated by antibodies but also on the target cells that respond to released and secreted mediators [18].

The route of allergen exposure is known to influence blood beta-tryptase levels, possibly in relation to the subtype of mast cell that the culprit allergen first encounters. Mast cells that predominate in the lungs and intestinal mucosa contain much less beta-tryptase per cell than those in connective tissues. This explains why beta-tryptase levels may correlate poorly in food anaphylaxis, for example [5].

While the role of mast cells in human anaphylaxis is rather definite, issues such the identification of the chemotactic factors that attract eosinophils in the spleen and the major signaling mechanism(s) for eosinophil activation remain unraveled $[13,19]$.

The aim of this study was to evaluate splenic eosinophil and mast cell accumulation using pagoda red and immunohistochemical staining in a series of anaphylaxis-related deaths that underwent medico-legal investigations. Our goal was to assess whether exposure to different types of injected allergens (antibiotics, contrast media and insect venoms) may trigger different cell activation signals and therefore be responsible for specific cell activation processes, specific immune cell migration and finally allergen-specific cell accumulation in the target organs.

\section{Materials and methods}

Selection of cases and control subjects

Two study groups were prospectively formed, an anaphylaxisrelated death (ARD) group and a control group (CG).

A total of 15 subjects (13 males, two females) with a mean age of 55 years (range 12-75 years) were included in the first group. Of these cases, five concerned fatal anaphylaxis following intramuscular antibiotic injections (different types of penicillin or cephalosporin). Six out of the 15 cases concerned individuals who had undergone diagnostic procedures with contrast medium administration (radiocontrast and gadolinium-based). In all these cases, arterial pressure markedly decreased approximately $3-10 \mathrm{~min}$ after contrast medium injection, patients became unresponsive and collapsed. Electromechanical dissociation arrest was evident on electrocardiogram and patients died between 45 and 90 min after loss of consciousness. Anaphylaxis to contrast material was suspected in all these cases.

Lastly, four out of the 15 cases concerned fatal anaphylaxis following insect stings.

The CG consisted of 40 age-, race- and gender-matched autopsy cases (32 males and eight females with a mean age of 55 years, range 18-92 years) with known, nonallergic causes of death.

Medical records and social histories of the deceased as well as police reports were reviewed consistently before conclusions were made.

Complete conventional autopsy, histology, toxicology and postmortem biochemistry were performed in all cases. Biochemical investigations were carried out in postmortem serum from femoral blood collected immediately prior to autopsy.

\section{Sample collection}

Peripheral blood was collected by aspiration through the femoral vein(s) prior to autopsy using a sterile needle and syringe. Blood was centrifuged immediately post collection at 3,000 $\mathrm{g}$ for $15 \mathrm{~min}$. After centrifugation, the separated supernatant (postmortem serum) was collected, stored in preservative-free tubes and frozen at $-20{ }^{\circ} \mathrm{C}$ until analysis. No specimens were excluded due to insufficient sample volume.

\section{Laboratory assays}

Biochemical investigations included measurement of betatryptase, total IgE and specific IgE in postmortem serum from femoral blood in all cases. Beta-tryptase and IgE was determined with a commercial fluoroenzyme immunoassay (FEIA) method (Pharmacia \& Upjohn, Freiburg, Germany). 
Histology

Representative samples of spleen tissue were obtained during autopsy in all cases. Conventional histology included haematoxylin-eosin (HE) stain, while eosinophils and mast cells were sought out with pagoda red (PR) stain. HE and PR stains were performed after tissue fixation in formaldehyde. Inflammatory nasal polyps were chosen as stain controls. Immunohistochemistry using anti-tryptase antibodies was performed on spleen tissue samples.

Splenic eosinophils, mast cells and degranulated mast cells were counted by two different pathologists in ten random X 40 fields.

\section{Statistical analysis}

Two-group comparison was performed nonparametrically by the Mann-Whitney $U$ test. $P$ values less than 0.05 were considered to indicate statistical significance. A nonparametric Spearman's rank correlation was used to evaluate the correlation between gender, age, beta-tryptase levels, total $\mathrm{IgE}$ values, splenic eosinophil, mast cell and degranulated mast cell numbers. GraphPad Prism 4.0 (GraphPad Software, La Jolla, CA, USA) was used for statistics.

\section{Ethical issues}

All relevant ethical issues were identified and previously discussed with the local ethical committee. All cases collected for this study underwent medico-legal autopsies as requested by the public prosecutor. Toxicology, histology and biochemistry, including beta-tryptase, total IgE and specific IgE measurements, were performed as part of the medico-legal investigations. All biological samples were anonymized prior to analysis. No further ethical approval was necessary to perform biochemical investigations in the selected cases.

\section{Results}

Table 1 summarizes the main postmortem investigation results pertaining to the ARD and control groups.

Main macroscopic findings in ARD cases consisted of pulmonary oedema and generalized visceral congestion. Splenomegaly and brain swelling were also frequently observed. Histologically, splenic eosinophils, mast cells, and degranulated mast cells were observed, with degranulated mast cells mainly located in spleen sinuses (Fig. 1a, b). Immunohistochemistry confirmed the presence of mast cells in the spleen. Toxicology did not provide any evidence of drug intoxication. However, toxicological analyses confirmed the presence of contrast media in peripheral blood in

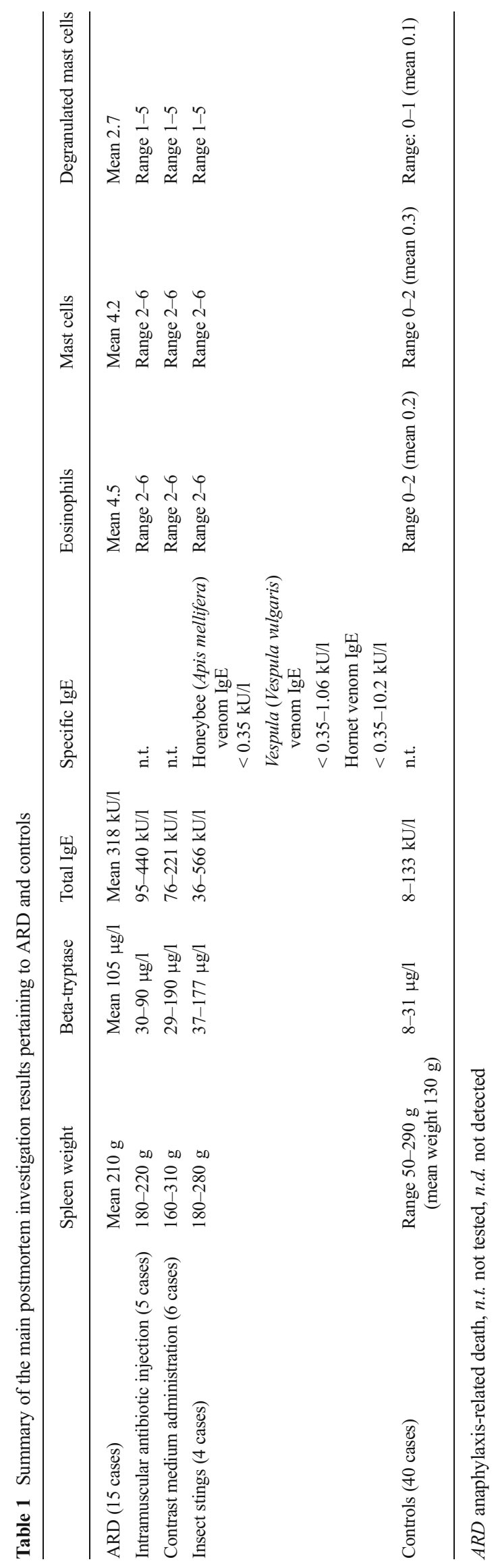




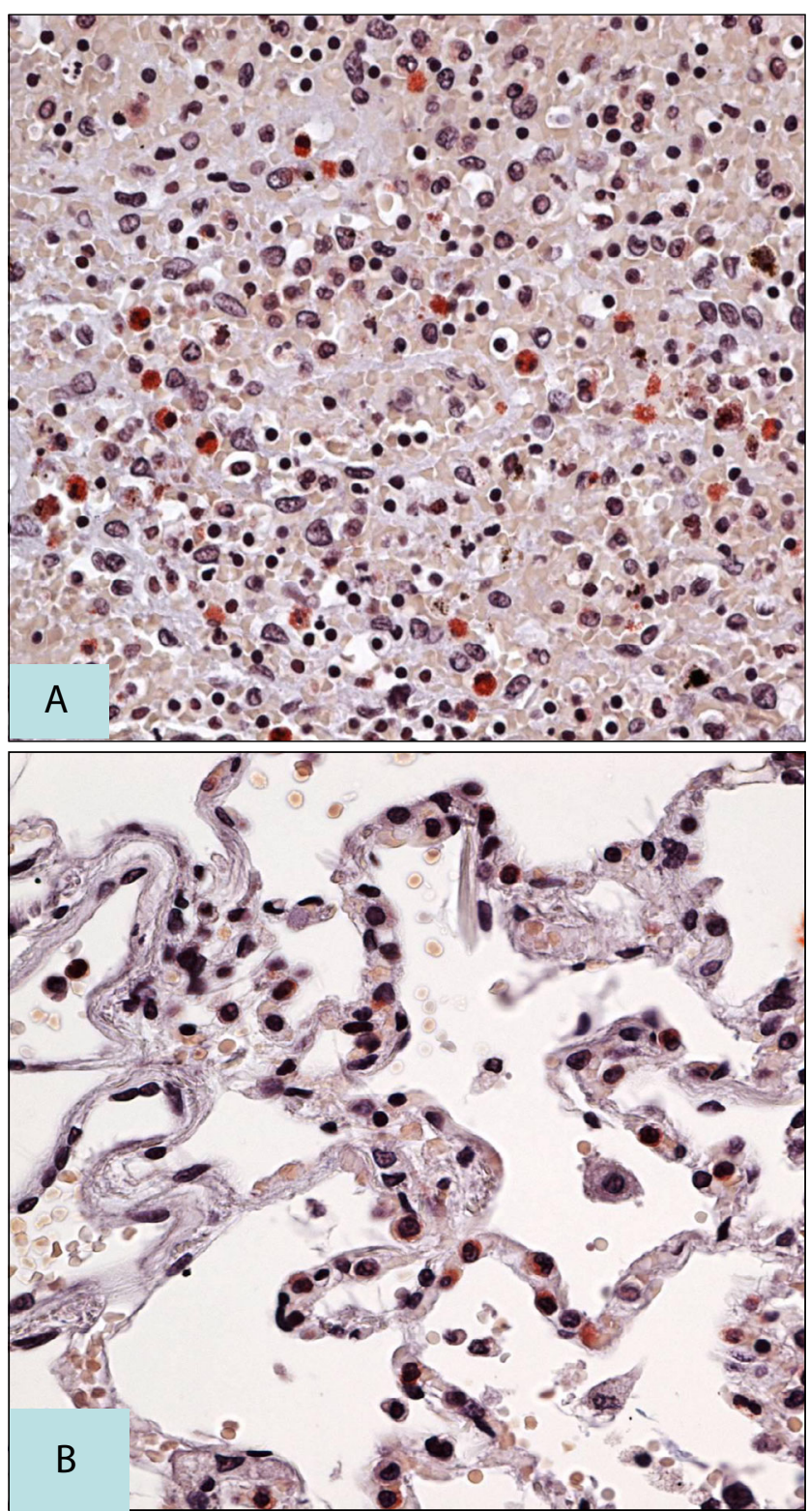

Fig. 1 Pagoda red stain. Massive presence of eosinophils and mast cells with characteristic degranulation in spleen tissue (a-20 HPF) and in interstitial space of the lungs (b-30 HPF). Note the red cells and red granules

correspondence with their administration in all cases that had undergone diagnostic procedures with contrast medium administration. Moreover, blood contrast material concentrations were consistent with the doses routinely administered for diagnostic purposes as well as with those documented in the medical records of each case.

Biochemical results showed increased postmortem serum beta-tryptase and total IgE levels above the clinical reference value, accompanied in some cases (Table 1) by increased specific IgE (Vespula venom IgE and hornet venom $\operatorname{IgE}$ ) concentrations, which allowed the hypothesis of fatal anaphylaxis following insect sting to be confirmed.
Postmortem investigations did not provide any evidence for other possible causes of death. Hence, the cause of death was determined to be anaphylaxis in all cases of this group.

In the control group, postmortem serum beta-tryptase levels were lower than the clinical reference value $(13.5 \mu \mathrm{g} /$ 1) in most cases. In only two cases (one traumatic death due to a traffic accident and one natural death with diffuse coronary atherosclerosis and myocardial infarction) did beta-tryptase concentrations appear higher than the clinical reference value, though with normal total $\mathrm{IgE}$ concentrations. In five out of 40 cases, total IgE was higher than the clinical reference values $(5-50 \mathrm{kU} / \mathrm{l})$, though with normal betatryptase concentrations. Histology and immunohistochemistry failed to show increased mast cells and eosinophils in spleen tissue samples. Based on all postmortem investigation findings, anaphylaxis as the cause of death was excluded in all cases of this group.

As expected, all tested parameters (spleen weight, betatryptase and total IgE levels as well as eosinophil, mast cell and degranulated mast cell numbers in the spleen) were significantly higher in the ARD group compared to those of the control group $(P<0.001$ for all tested parameters).

In the ARD cases, no statistically significant differences were observed among the various groups (intramuscular antibiotic injection, intravenous contrast medium administration and stinging insects) in any combination. This suggested that mast cell and eosinophil accumulation in the spleen during anaphylaxis does not have any specific pattern related to the triggering allergen.

Lastly, no gender-related or age-dependent differences were observed in beta-tryptase levels, total IgE values, splenic eosinophil, mast cell and degranulated mast cell numbers in either the ARD or control group.

\section{Discussion}

Anaphylaxis is an acute, life-threatening, systemic reaction with varied mechanisms, clinical presentations and degrees of severity that results from the sudden systemic release of mast cell and basophil mediators. In the clinical setting, the diagnosis is supported by suggestive clinical symptoms after exposure to potential triggering agents or events and laboratory investigations, mainly plasma histamine and beta-tryptase determination [5, 18, 20-23].

In the postmortem field, the identification of fatal anaphylaxis can be extremely challenging due to incomplete medical records, nonspecific macroscopic and microscopic findings as well as limited reliable laboratory investigations. Hence, much effort has been made to identify the most suitable combination of microscopic findings and biochemical results that would allow for a suitable diagnosis of anaphylaxis-related deaths $[5,8,9,13,24-30]$. 
Observations concerning the accumulation of eosinophils in the spleen in cases of human fatal anaphylactic shock were first made in 1966 by Voigt [6], who postulated that high splenic eosinophil count might be a sign of generalized eosinophilia as part of an allergic condition.

Increased numbers of eosinophils were subsequently observed by Delage and Irey [12] in the red pulp of the spleen in anaphylactic deaths using common histochemical stain.

While eosinophil infiltrates clearly appeared as an aftermath of anaphylaxis in sensitized tissues re-exposed to specific antigens, the identification of the biochemical changes responsible for eosinophil migration into tissues and their specific functions during anaphylaxis remained an unsolved issue for a long time.

In recent years, the presence of eosinophils, mast cells and degranulated mast cells in the spleen of individuals dying in the course of hypersensitivity reactions has been reaffirmed as a characteristic, morphological feature of anaphylactic deaths [13-16].

Trani et al. [14] identified splenic mast cells and eosinophils in four cases of anaphylaxis-related death following intramuscular antibiotic injections (penicillin and cephalosporin) using the pagoda red stain. Edston [13] observed that pagoda red does not discriminate between eosinophils and mast cells and is not as sensitive as immunohistochemical staining using monoclonal antibodies. Hence, he recommended that splenic tissue be systematically sampled for immunohistochemical examination in all cases of unwitnessed sudden death, concluding that eosinophil and mast cell accumulation in splenic red pulp, along with increased postmortem serum beta-tryptase levels, should be considered the most reliable combination of microscopic findings and biochemical results to diagnose fatal anaphylaxis after death.

Eosinophils reside in mucosal tissues and are well characterized as effector cells in helminth infections. They express a wide array of cell-surface molecules, including immunoglobulin receptors for IgG and IgA, complement receptors, cytokine receptors, chemokines, adhesion molecules and leukotriene receptors. Like other haematopoietic cells, eosinophils express low-affinity IgE receptors (FceRII). The expression of high-affinity IgE receptors $(\mathrm{Fc} \varepsilon \mathrm{RI})$ on their surface is minimal does not seem to be responsible for cell activation and is of uncertain functional significance $[18,19,31-33]$.

Two allergic conditions have been specifically associated with eosinophil activation, i.e. allergic bronchial asthma and eosinophilic esophagitis [18]. The number of eosinophils is also increased in atopic dermatitis and rhinosinusitis. These observations notwithstanding, the physiological and pathological roles of eosinophils in allergies are not completely understood and remain a pressing issue of research [34].

While the accumulation of eosinophils and mast cells in the spleen during hypersensitivity reactions appears to be a hallmark of anaphylaxis and anaphylactic death, it is still unclear whether their presence is the consequence of recruitment through locally released chemotactic factors or whether it reflects a general increase of those cells in circulating blood and tissue due to an allergic disposition [13].

Eosinophils release proinflammatory mediators, i.e. granule-stored cationic protein and interleukin-4 as well as newly synthesized eicosanoids and cytokines. In eosinophilmediated diseases, eosinophil cationic protein plays a role in host defence and pathogenesis. Moreover, eosinophil activation may result in tissue damage [19]. Cell-free eosinophil granules are present extracellularly in situations characterized by tissue eosinophil infiltration, including asthma, but have unknown functional capabilities [35].

The molecular interactions between mast cells and eosinophils in allergic inflammatory responses have evoked increasing research interests [25]. Mast cell activation and degranulation during allergy is responsible for the release of numerous effector molecules. Some of these molecules could act as eosinophil chemotactic factors and consequently be responsible for eosinophil accumulation in the spleen [19, 31-33]. Using basophil- and eosinophil-depleted mouse models, Matsuoka et al. have recently postulated the role of basophils and eosinophils as initiators and effectors, respectively, in $\operatorname{IgE}$ chronic allergic inflammation [36].

The results of our investigations concur with those of former studies, emphasizing the diagnostic usefulness of increased splenic eosinophil and mast cells for the postmortem identification of anaphylaxis-related deaths following exposure to different types of intramuscularly and intravenously injected allergens.

Despite a lower sensitivity than immunohistochemical staining with monoclonal antibodies in discriminating eosinophil and mast cells, pagoda red stain allowed these cells to be identified in the spleen and could therefore be proposed as a low-cost, first-line diagnostic procedure in those situations where immunohistochemistry is not systematically performed or cannot be carried out.

Concerning the main purpose of our study in the spleen, specific eosinophil/mast cell accumulation patterns in relation to the triggering allergens could not be identified.

The exact role eosinophils play in the course of anaphylaxis remains unclear, though their accumulation in the spleen can be considered a reliable diagnostic marker in the postmortem setting. The identification of organs and tissues that are involved in anaphylaxis in splenectomized subjects could therefore be a topic of interest and future research.

Since circumstantial data and clinical information are often unavailable in forensic pathology routine, anaphylaxis should always be suspected in all cases of sudden, unexpected death. As shown by our results as well as those of previous studies on this topic, biochemistry, histology and immunohistochemistry can provide useful diagnostic information and render the 
conclusion of anaphylaxis-related death reasonably legitimate once other potential causes of death have been excluded.

Lastly, the limitations of our study must be acknowledged. The most important is the relatively small number of subjects, which may limit research accuracy. However, precise selection criteria were applied during the recruitment process in order to minimize heterogeneity in the study populations. Prospective investigations including a greater number of subjects are therefore needed to confirm or invalidate our findings.

Acknowledgments Authors are grateful to the anonymous reviewers, whose constructive and useful comments improved the quality of the article.

A special thank goes to Professor G. Barbolini, mentor of the pagoda red stain, and to the staff of the Laboratory of the Anatomia Patologica of Modena for the appreciable contribution to the staining procedure, with particular mention of Elisabetta Mattioli, Francesca Mazzei, Federica Federico, Rosa Zaramella and Silvia Malaguti.

Role of funding source This study was not financially supported.

Conflict of interest The authors disclose any financial and personal relationship with other people or organizations that could potentially or inappropriately influence their work and conclusions.

\section{References}

1. Farnam K, Chang C, Teuber S, Gershwin ME (2012) Nonallergic drug hypersensitivity reactions. Int Arch Allergy Immunol 159:327345

2. Johansson SG, Hourihane JO, Bousquet J, Bruijnzeel-Koomen C, Dreborg S, Haahtela T, Kowalski ML, Mygind N, Ring J, van Cauwenberge P, van Hage-Hamsten M, Wüthrich B (2001) A revised nomenclature for allergy. An EACCI position statement from the EACCI nomenclature task force. Allergy 56:813-824

3. Johansson SG, Bieber T, Dahl R, Friedmann PS, Lanier BQ, Lockey RF, Motala C, Ortega Martell JA, Platts-Mills TA, Ring J, Thien F, Van Cauwenberge P, Williams HC (2004) Revised nomenclature for allergy for global use: report of the nomenclature review Committee of the World Allergy Organization, October 2003. J Allergy Clin Immunol 113:832-836

4. Khan BQ, Kemp SF (2011) Pathophysiology of anaphylaxis. Curr Opin Allergy Clin Immunol 11:319-325

5. Palmiere C, Comment L, Mangin P (2014) Allergic reactions following contrast material administration: nomenclature, classification, and mechanisms. Int J Legal Med 128:95-103

6. Herbst J, Heath K, Heddle R, Gilbert JD, Byard RW (2013) Multiple bee stings, peritumoral mast cell degranulation and anaphylaxis-is there a relationship? J Forensic Legal Med 20:591-594

7. Shen Y, Li L, Grant J, Rubio A, Zhao Z, Zhang X, Zhou L, Fowler D (2009) Anaphylactic deaths in Maryland (United States) and Shangai (China): a review of forensic autopsy cases from 2004 to 2006. Forensic Sci Int 186:1-5

8. Pumphrey RS, Roberts IS (2000) Postmortem findings after anaphylactic reactions. J Clin Pathol 53:273-276

9. Da Broi U, Moreschi C (2011) Post-mortem diagnosis of anaphylaxis: a difficult task in forensic medicine. Forensic Sci Int 204:1-5

10. Voigt J (1966) Eosinophils in the spleen in cases of lethal anaphylactic shock. Med Sci Law 6:162-163
11. Delage C, Irey NS (1972) Anaphylactic deaths: a clinicopathologic study of 43 cases. J Forensic Sci 17:525-540

12. Perskvist N, Edston E (2007) Differential accumulation of pulmonary and cardiac mast cell-subsets and eosinophils between fatal anaphylaxis and asthma death: a postmortem comparative study. Forensic Sci Int 169:43-49

13. Edston E (2013) Accumulation of eosinophils, mast cells, and basophils in the spleen in anaphylactic deaths. Forensic Sci Med Pathol 9: 496-500

14. Trani N, Bonetti LR, Gualandri G, Barbolini G (2008) Immediate anaphylactic death following antibiotics injection: splenic eosinophilia easily revealed by pagoda red stain. Forensic Sci Int 181:21-25

15. Sterzik V, Drendel V, Will M, Bonhert M (2012) Suicide of a man with known allergy to fish protein by ingesting tinned fish. Forensic Sci Int 221:e4-e6

16. Roncati L, Barbolini G, Scacchetti AT, Busani S, Maiorana A (2013) Unexpected death: anaphylactic intraoperative death due to Thymoglobulin carbohydrate excipient. Forensic Sci Int 228:e28e32

17. Kounis NG, Soufras GD, Hahalis G (2014) Accumulation of eosinophils, mast cells, and basophils in the spleen and the coronary arteries in anaphylactic deaths: is the Kounis hypersensitivity associated syndrome present? Forensic Sci Med Pathol 10:150-151

18. Jönnson F, Daëron M (2012) Mast cells and company. Front Immunol 3:16

19. Stone KD, Prussin C, Metcalfe DD (2010) IgE, mast cells, basophils, and eosinophils. J Allergy Clin Immunol 125(2 Suppl 2):S73-S80

20. Lieberman P, Nicklas RA, Oppenheimer J (2010) The diagnosis and management of anaphylaxis practice parameter: 2010 update. J Allergy Clin Immunol 126:477-480

21. Sala-Cunill A, Cardona V, Labrador-Horrillo M, Luengo O, Esteso O, Garriga T, Vicario M, Guilarte M (2013) Usefulness and limitations of sequential serum tryptase for the diagnosis of anaphylaxis in 102 patients. Int Arch Allergy Immunol 160:192-199

22. Jönsson F, Mancardi DA, Kita Y, Karasuyama H, Iannascoli B, Van Rooijen N, Shimizu T, Daëron M, Bruhns P (2011) Mouse and human neutrophils induce anaphylaxis. J Clin Invest 121:1484 1496

23. Jönsson F, Mancardi DA, Zhao W, Kita Y, Iannascoli B, Khun H, van Rooijen N, Shimizu T, Schwartz LB, Daëron M, Bruhns P (2012) Human Fc $\gamma$ RIIA induces anaphylactic and allergic reactions. Blood 119:2533-2544

24. Yunginger JW, Nelson DR, Squillace DL, Jones RT, Holley KE, Hyma BA, Biedrzycki L, Sweeney KG, Sturner WQ, Schwartz LB (1991) Laboratory investigations of death due to anaphylaxis. J Forensic Sci 36:857-865

25. Edston E, van Hage-Hamsten M (1998) Beta-tryptase measurements post-mortem in anaphylactic deaths and in controls. Forensic Sci Int 93:135-142

26. Edston E, Eriksson O, van Hage M (2007) Mast cells tryptase in postmortem serum - reference values and confounders. Int J Legal Med 121:275-280

27. Mayer DE, Krauskopf A, Hemmer W, Moritz K, Jarisch R, Reiter C (2011) Usefulness of post mortem determination of serum tryptase, histamine and diamine oxidase in the diagnosis of fatal anaphylaxis. Forensic Sci Int 212:96-101

28. Luongo S, Frontalini C, Pesaresi M, Valsecchi M, Tagliabracci A (2011) Histopathological markers for the diagnosis of anaphylactic death. Med Sci Law 51:30-36

29. Edston E, van Hage-Hamsten M, Johansson SG (1996) Tryptase - at last a useful diagnostic marker for anaphylactic death. Allergy 51: 443-445

30. Nishio H, Takai S, Miyazaki M, Horiuchi H, Osawa M, Uemura K, Yoshida K, Mukaida M, Ueno Y, Suzuki K (2005) Usefulness of serum mast cell-specific chymase levels for postmortem diagnosis of anaphylaxis. Int J Legal Med 119:331-334 
31. Prussin C, Metcalfe DD (2006) IgE, mast cells, basophils, and eosinophils. J Allergy Clin Immunol 117:S450-S456

32. Seminario MC, Saini SS, MacGlashan DW Jr, Bochner BS (1999) Intracellular expression and release of Fc epsilon RI alpha human eosinophils. J Immunol 162:6893-6900

33. Kita H, Kaneko M, Bartemes KR, Weiler DA, Schimming AW, Reed CE, Gleich GJ (1999) Does IgE bind to and activate eosinophils from patients with allergy? J Immunol 162:6901-6911
34. Simon HU (2013) Allergic inflammation: focus on eosinophils. Allergy 68:823-824

35. Broide DH, Finkelman F, Bochner BS, Rothenberg ME (2011) Advances in mechanisms of asthma, allergy, and immunology in 2010. J Allergy Clin Immunol 127:689-695

36. Matsuoka K, Shitara H, Taya C, Kohno K, Kikkawa Y, Yonekawa H (2013) Novel basophil- or eosinophil-depleted mouse models for functional analyses of allergic inflammation. PLoS One 8:e60958 